\title{
Breast Ductal Endoscopy: Do Not Neglect Education
}

\author{
George C. Zografos Flora Zagouri Theodoros N. Sergentanis \\ Breast Unit, 1st Department of Propaedeutic Surgery, Hippokratio Hospital, University of Athens, Greece
}

Dear Editor,

Ductal endoscopy of the breast is a recent method of ever growing importance in the work-up of patients with bloody nipple discharge. Ductal endoscopy can produce enlarged, high-quality, real time video images of tiny, previously unseen areas of the breast ductal system [1-4].

Education in breast ductal endoscopy has not been systematically addressed in the literature. Cannulating the bifurcations in the breast ducts might be a demanding task. Given the particularities of the method and the lack of knowledge, the optimal training model has not yet been determined. In this study, the training program performed in our Breast Unit is introduced and probably recommended. For the training process, an ex vivo model was adopted. Fellows were trained on surgical specimens derived from modified radical mastectomy for breast cancer. Each specimen was submitted to ductoscopy (Mastascope $^{\mathrm{TM}}$, Lifeline Biotechnologies, Inc., Reno, NV, USA), fresh, within $20 \mathrm{~min}$ after excision, and was free from any form of fixation. Under adequate illumination, the mastectomy specimen was mounted on a flat surface to simulate the anatomical position on a supine body. The target of the education program was to achieve proficiency in performing ductoscopy.

Ductal endoscopy was considered successful when the fellow was able to: i) Perform mapping of the ductal system. Mapping comprised noting down the location and number of ducts can- nulated and avoiding to cannulate the same duct more than once, in the same breast specimen. Additionally, mapping encompassed recording the distance of scope advancement and the number of bifurcations passed for each duct. ii) Locate and identify the accessible intraductal lesions. However, it should be kept in mind that ductal endoscopy on ex vivo specimens is more difficult than on live patients due to less distensible ducts, which render the visualization of pathology more difficult.

Nevertheless, this letter points to the need for studies on education prior to ductal endoscopy. Comparative studies with training models on live patients might be desirable. The optimal education scheme, putatively combining ex vivo and in vivo education, remains to be defined.

\section{References}

Hunerbein M, Estevez Schwarz L, Schneider U, Schlag PM: Evaluation of pathologic nipple discharge with ductoscopy. J Am Coll Surg 2003;197:697-698.

$\checkmark 2$ Yamamoto D, Shoji T, Kawanishi H, Nakagawa H, Haijima H, Gondo H, Tanaka $\mathrm{K}$ : A utility of ductography and fiberoptic ductoscopy for patients with nipple discharge. Breast Cancer Res Treat 2001;70:103-108.

3 Jacobs VR, Paepke S, Ohlinger R, Grunwald S, Kiechle-Bahat, M: Breast ductoscopy: technical development from a diagnostic to an interventional procedure and its future perspective. Onkologie 2007;30:545-549.

4 Grunwald S, Heyer H, Paepke S, Schwesinger G, Schimming A, Hahne M, Thomas A, Jacobs VR, Ohlinger R: Diagnostic value of ductoscopy in the diagnosis of nipple discharge and intraductal proliferations in comparison to standard methods. Onkologie 2007;30:243-248.

\begin{tabular}{ll}
\hline KARGER & $\oplus$ 2008 S. Karger GmbH, Freiburg \\
Fax +49 761 4520714 & Accessible online at: \\
$\begin{array}{l}\text { E-mail Information@Karger.de } \\
\text { www.karger.com }\end{array}$ & www.karger.com/onk
\end{tabular}

